\title{
A livre adesão nas cooperativas de crédito: estamos captando cooperados ou correntistas?
}

Free Access In credit cooperatives: are we capturing cooperates or account holders?

\begin{abstract}
Resumo
A presente pesquisa objetivou propor uma discussão referente à adoção do princípio da adesão voluntária e livre com os possíveis impactos financeiros e educacionais nas cooperativas de crédito de Belém, a partir da percepção dos seus gestores, buscando conhecer os objetivos dessa estratégia de captação de novos sócios. Fezse uso da técnica de pesquisa análise de conteúdo pela qual foram desenvolvidas duas categorias de análise, $1^{\mathfrak{a}}$ ) Quem são nossos cooperados? 2 ${ }^{\mathrm{a}}$ ) Vantagens e Desvantagens da Livre Adesão. Os resultados evidenciam que a adoção ao princípio da adesão voluntária e livre apresentou impactos positivos sobre o aspecto financeiros observado pelo aumento do quadro social e do capital social com a integralização das cotas partes. Evidenciou-se também que algumas cooperativas estão preocupadas com a educação cooperativa desses novos sócios, pois deve-se ter cuidado em preservar a essência do cooperativismo e cuidar para que as cooperativas não se transformem em bancos comerciais.
\end{abstract}

Palavras-chave: Cooperativas de crédito, adesão voluntária e livre, cooperativismo.

\begin{abstract}
The present research aimed to propose a discussion regarding the adoption of the principle of voluntary and free access with the financial and educational impacts in the credit cooperative of Belém, from the perception of its managers, seeking to know the objectives of this strategy to attract new members. The content analysis research technique was used by which two categories of analysis were developed. 1) Who are our members? 2) Advantages and Disadvantages of Free Access. The results show that the adoption of the principle of voluntary and free access had positive impacts on the financial aspect observed by the increase of the membership and share capital with the payment of the shares. It was also evident that some cooperatives are concerned with the cooperative education of these new members, as care must be taken to preserve the essence of cooperativism and to ensure that cooperatives do not become commercial banks.
\end{abstract}

Keywords: Credit cooperative, voluntary and free access, cooperativism.

Maria Iolanda Santos SouzaI, Anderson Roberto Pires e SilvaII, Cássia Marcelle Dias Pinho ${ }^{\mathrm{III}}$

I Universidade Federal do Pará - UFPA. Pará, PA. iol.miss@hotmail.com

II Universidade Federal do Pará - UFPA. Pará, PA. andersonpires@hotmail.com

III Universidade Federal do Rio Grande do Norte (UFRN). Natal, RN. pinhocmdp@gmail.com 


\section{Introdução}

Os princípios são os meios pelos quais as cooperativas colocam em prática os valores de solidariedade, responsabilidade, democracia e igualdade, visando o bem-estar socioeconômico dos seus cooperados (OCB, 2018). Para Cançado e Gontijo (2005) os princípios do cooperativismo são o que diferenciam essas sociedades das demais sociedades empresariais. Singer (2002) complementa que os princípios e valores sociais do cooperativismo são considerados como base para essas sociedades. Nesse contexto, as cooperativas possuem como princípios de sua gestão a Adesão Voluntária e Livre; a Gestão Democrática; a Participação Econômica dos Membros; a Autonomia e Independência; a Educação, Formação e Informação; a Intercooperação e o Interesse pela Comunidade (OCB, 2018).

Dentre os princípios do cooperativismo, chama-se atenção, nesse estudo, ao da Adesão Voluntária e Livre o qual no seu sentido literal nos remete que para associar-se a uma cooperativa, considera-se o interesse do indivíduo, tendo ele a opção de ser ou não um cooperado. Para Cançado e Gotijo (2005), este princípio considera a liberdade individual de cada pessoa, do poder dela ingressar numa sociedade cooperativa com a prerrogativa de também com essa mesma liberdade sair conforme seus interesses. Silva, Santos e Oliveira (2012) destacam essa liberdade ao ingressar na cooperativa, porém complementam que as pessoas precisam estar aptas a utilizarem os serviços, dispostas a assumirem responsabilidades como membros e preencherem as condições estabelecidas nos estatutos das cooperativas.

A Lei 5.764/71 em seu Art. 29, § 1ํㅡ, orienta que "A admissão dos associados poderá ser restrita, a critério do órgão normativo respectivo, às pessoas que exerçam determinada atividade ou profissão, ou estejam vinculadas a determinada entidade" sinalizando haver um sentido muito maior que o literal do princípio da adesão voluntária e livre. Assim, as cooperativas estabelecem restrições técnicas e ou profissionais para admissões de novos sócios, condicionando estas admissões a profissionais de um mesmo segmento ou de uma mesma classe profissional (MACHADO, 1975).

Diante da evolução significativa das normas que regem o cooperativismo, destacam-se a resolução no 3.106/2003 do Conselho Monetário Nacional (CMN), ora revogada, mas que iniciou uma abertura maior às cooperativas de crédito na admissão de novos associados, e a resolução no 4.434/2015 do CMN, atualmente em vigor, e que materializa o princípio da adesão livre e voluntária, quebrando a exigência de um mesmo perfil de associados para a constituição dessas cooperativas, abrindo para a livre admissão de associados (PORTAL DO COOPERATIVISMO FINANCEIRO, 2019).

Neste contexto, diversas cooperativas de crédito abriram seu capital para a admissão de novos sócios. No entanto, surge certa preocupação quanto ao aspecto financeiro da cooperativa e educacional do cooperado, referente a entrada desses associados. Assim, surge a seguinte questão de pesquisa: quais os possíveis impactos financeiros e educacionais que a adoção do princípio da adesão voluntária e livre pode provocar nas cooperativas de crédito da cidade de Belém/Pa?

A pesquisa objetiva propor uma discussão referente à adoção do princípio da adesão voluntária e livre com os possíveis impactos financeiros e educacionais nas cooperativas de crédito de Belém, a partir da percepção dos seus gestores, buscando conhecer os objetivos dessa estratégia de capitação de novos sócios e se esses foram alcançados.

O processo de implementação desse princípio vem sendo discutido nos fóruns, seminários e nas próprias assembleias gerais das cooperativas, porém não foi encontrada nenhuma literatura com um teor mais científico dos impactos que essa adoção pode trazer para as cooperativas, o que caracteriza a originalidade da presente pesquisa.

Entende-se que a adesão voluntária e livre pode provocar diversos impactos em uma sociedade cooperativa, uma vez que, a entrada e ou saída dos sócios provoca alterações no quadro social e na própria operacionalização da cooperativa, pois o cooperado é dono, cliente e até fornecedor da sociedade cooperativa da qual faz parte. No entanto, este estudo focou nos possíveis impactos 
financeiros e educacionais, com a perspectiva de que os resultados possam contribuir principalmente com o processo da educação cooperativa para os novos sócios a fim de que eles assumam a função de sócio-cooperado e não se restrinjam apenas à condição de correntista.

As cooperativas de crédito apresentam um crescimento de quase duas vezes mais que os bancos comerciais e estão presentes em 95\% dos municípios brasileiros, sendo 620 desses municípios tendo a cooperativa de crédito como única instituição financeira presente (OCB, 2018). De posse dos balanços patrimoniais e de estatutos de algumas cooperativas de crédito foi identificado certo aumento no quadro social com a admissão tanto de pessoas físicas quanto de pessoas jurídicas como novos sócios cooperados, estando assim, de acordo com o relatório de gestão OCB de 2018, que apresentou no Sistema Nacional de Crédito Cooperativo (SNCC) um aumento na adesão de pessoas físicas de $76 \%$ e de pessoa jurídica foi de $120 \%$, assim, justifica-se a escolha e relevância do ramo de crédito (OCB, 2018).

\section{Cooperativas}

As cooperativas são sociedades de pessoas, que encontram na união e na prática da democracia atender suas necessidades, diferentemente das empresas capitalistas que visam o capital. Na visão de Meinen e Port (2012), cooperativa é uma associação autônoma de pessoas, democraticamente controladas, que espontaneamente unem-se, a fim de suprir suas necessidades em comum, tanto econômicas, como sociais e culturais. Pinho (2004) corrobora que o cooperativismo não somente visa o meio econômico-social dos seus associados com a prestação direta de serviços, como também indiretamente, visto que esta prestação atinge a comunidade e os associados são parte desta.

Para facilitar a organização, representação e atuação das cooperativas, em maio de 1993 foi aprovado pelo Conselho Diretor da OCB a divisão em ramos baseada nas diferentes áreas de atuação do movimento, totalizando 13 ramos: Agropecuário, Consumo, Crédito, Educacional, Especial, Habitacional, Infraestrutura, Mineral, Produção, Saúde, Trabalho, Transporte e Turismo e Lazer e em todos esses ramos ficou comprovada a competitividade do modelo e a sua contribuição junto a sociedade. No entanto, em 2019 baseado na justificativa de melhorar a representatividade das cooperativas, assim como o processo de comunicação entre as mesmas, a OCB aprovou a Resolução № 56/2019 que dá uma nova regulamentação e classificação aos ramos do cooperativismo que agora são classificados em sete ramos: Trabalho, Produção de Bens e Serviços, Crédito, Transporte, Agropecuário, Saúde, Consumo e Infraestrutura, destaque para as cooperativas de crédito que hoje são consideradas o segundo maior ramo ficando atrás apenas para as cooperativas Agropecuárias (SICOOB, 2019).

As cooperativas de crédito têm o registro de surgimento na Alemanha, por volta do ano de 1850, com a finalidade inicial de atender às necessidades dos trabalhadores rurais, posteriormente alcançando aos que desenvolviam atividades também na área urbana (GERIZ, 2004). Os principais precursores foram Herman Schulze (1818-1883) que fundou os bancos populares nas cidades; e Frederico Raiffeisen (1818-1888) considerado o precursor do cooperativismo de crédito rural por ter idealizado as Caixas Rurais Raiffeisen (HÖFFLING, 2013). No Brasil, surge em 1902, em Nova Petrópolis, no estado do Rio Grande do Sul, baseada no modelo Raiffeisen, pelo padre suíço Theodor Amstadt (GERIZ, 2004).

Observa-se que as cooperativas de crédito vêm destacando-se entre as Instituições Financeiras do Brasil, por oferecerem os mesmos produtos e serviços que os Bancos Comerciais, no entanto com diferenciais tais como, possuir isenção ou redução de algumas taxas, direito a voto e principalmente a participação nas sobras ao final de cada exercício (MACEDO; FREIRE, 2017). Organizam-se "através de uma estrutura que tem como base sistemas interligados de cooperativas singulares e centrais" (GERIZ, 2004, p. 99). Macedo e Freire (2017) apontam que os sistemas objetivam melhorar a viabilidade econômica das cooperativas.

No entendimento do Banco Central do Brasil (BACEN), as cooperativas de crédito funcionam como uma instituição financeira formada pela união de pessoas que trabalham conjuntamente para os 
seus interesses com o intuito de prestação de serviços financeiros igualmente como encontrado nos bancos comerciais, como conta corrente, aplicações financeiras, cartão de crédito, empréstimos e financiamento. No entanto, não pode-se esquecer das diferenças de valores e princípios existentes entre os bancos comerciais e as cooperativas de crédito (BACEN, 2q019).

As Cooperativas de crédito estão em constante crescimento, dados do Banco Central do Brasil (2016) evidenciam que existem 1.017 Singulares, 35 Centrais, 4 Confederações e 2 Bancos Cooperativos (Banco Cooperativo do Brasil S. A. - Bancoob e Banco Cooperativo Sicredi S. A. Bansicredi). A Região Norte foi a que teve o maior crescimento em números de cooperativas, passou de 83 para 178 de 2012 até 2016. De acordo com a OCB/PA (2018) as cooperativas atuantes atendem $17 \%$ dos municípios do estado com 11 Cooperativas, reunindo 31.386 cooperados e empregando 320 profissionais atuando nesse ramo.

\section{Princípios Cooperativistas}

Os princípios cooperativistas formulados pelos pioneiros de Rochdale, em 1844, representam significativa importância na história do cooperativismo, passaram por um processo de aperfeiçoamento, assim permanecendo até os dias atuais. Para Macedo e Freire (2017) as próprias transformações econômicas e sociais foram conduzindo os princípios cooperativistas ao longo do tempo ao que temos hoje, sendo sua última retificação em Manchester, Inglaterra, no ano de 1995. Bertuol, Cançado e Souza (2012) conceituam os Princípios cooperativistas como sendo as leis que regem todo o arcabouço do cooperativismo no qual os associados são conduzidos a segui-los, desse modo mantendo a organização cooperativista.

Antes da cooperativa de Rochdale existiram as protocooperativas, porém o que a diferenciou das demais foi que o seu planejamento, no qual foram idealizados princípios e valores para nortear o movimento, tomou forma de documento, hoje conhecido como estatuto (CANÇADO; SOUZA; PEREIRA, 2014). Schneider (2012) complementa que os pioneiros de Rochdale formularam os seus estatutos coletivamente de forma bem elaborada, durante o tempo de um ano, no qual os valores e princípios foram pensados e definidos como essência do movimento cooperativista e os impuseram e propagaram com sucesso.

Os princípios cooperativistas, na verdade são a materialização de valores defendidos pelos pioneiros de Rochdale que permanecem até os dias atuais. "Os valores constituem as ideias-força a partir das quais emanam a energia motivadora e a inspiração para a ação cooperativa, que é regida por princípios" (SCHNEIDER, 2012, p. 258). Os princípios cooperativistas são as linhas orientadoras através das quais as cooperativas levam à prática os seus valores (DEWANGAN; DIXIT, 2018; PORTAL DO COOPERATIVISMO FINANCEIRO, 2019).

Em 1895 surge uma organização que passa a ser responsável por toda discussão do movimento cooperativista, dos valores e dos princípios que os orientam, a Aliança Cooperativa Internacional - ACI, em Londres, Inglaterra (Schneider, 1999). A ACI é a encarregada de manter os princípios essenciais e adaptar os demais às circunstâncias mutáveis e às peculiaridades de cada região e cultura (SCHNEIDER, 2012); é uma organização não-governamental que objetiva unir, representar e atender todas as cooperativas no ambiente global (ACI, 2019).

A ACI promoveu Congressos nos anos de 1937 em Paris, 1966 em Viena e 1995 em Manchester, nos quais os princípios cooperativistas foram revisados, desde Rochdale, registrando as mais importantes modificações, com o empenho de adaptá-los a cada época, sem perder as características essenciais e a cada reunião promovida havia a discussão dos princípios com a participação de representantes de cooperativas dos diversos países e pesquisadores que discutiam bastante afim de se chegar a decisão mais acertada para o crescimento do cooperativismo (SCHNEIDER, 2012). 
No Congresso de Manchester, 1995, segundo Charterina (1995), a ACI destacou o empenho das cooperativas em encontrar sua própria identidade, com isso, antecipadamente, ocorreu o planejamento do estudo em relação a modificação dos princípios a partir dos valores.

Assim, após vários esboços, em Manchester é apresentado o documento o que se encontrava dividido em duas partes: o primeiro foi intitulado "Declaração da Aliança Cooperativa Internacional sobre Identidade Cooperativa", considerado o documento principal e inclui a definição de cooperativa, a lista de valores e a definição e enunciação de princípios cooperativos; e o segundo que foi intitulado "Relatório sobre a Declaração da ACI sobre Identidade Cooperativa" cujo papel foi complementar, interpretar e esclarecer o principal (CHARTERINA, 1995).

Quadro 1 - Evolução dos Princípios Cooperativistas segundo a Aliança Cooperativa Internacional

\begin{tabular}{|c|c|c|c|}
\hline \multirow{2}{*}{$\begin{array}{l}\text { Estatuto de } 1844 \\
\text { (Rochdale) }\end{array}$} & \multicolumn{3}{|c|}{ Congresso da Aliança Cooperativa Internacional } \\
\hline & 1937 (Paris) & 1966 (Viena) & 1995 (Manchester) \\
\hline $\begin{array}{l}\text { 1. Adesão Livre } \\
\text { 2.Gestão Democrática } \\
\text { 3.Retorno Pro-Rata das } \\
\text { Operações } \\
\text { 4.Juro Limitado ao } \\
\text { Capital investido } \\
\text { 5.Vendas a Dinheiro } \\
\text { 6.Educação dos Membros } \\
\text { 7.Cooperativização Global }\end{array}$ & $\begin{array}{l}\text { a) Princípios Essenciais de } \\
\text { Fidelidade aos } \\
\text { Pioneiros } \\
\text { 1. Adesão aberta } \\
\text { 2. Controle ou } \\
\text { Gestão Democrática } \\
\text { 3. Retorno Pro-rata das } \\
\text { Operações } \\
\text { 4. Juros Limitados ao } \\
\text { Capital } \\
\text { b) Métodos Essenciais de } \\
\text { Ação e Organização } \\
\text { 5. Compras e Vendas à } \\
\text { Vista } \\
\text { 6. Promoção da Educação } \\
\text { 7.Neutralidade Política e } \\
\text { Religiosa. }\end{array}$ & $\begin{array}{l}\text { 1. Adesão Livre } \\
\text { (Inclusive neutralidade } \\
\text { política, religiosa, racial e } \\
\text { social) } \\
\text { 2. Gestão Democrática } \\
\text { 3. Distribuição das Sobras: } \\
\text { a) ao desenvolvimento da } \\
\text { cooperativa; } \\
\text { b) aos serviços comuns; } \\
\text { c) aos associados pro-rata } \\
\text { das operações } \\
\text { 4. Taxa Limitada de Juros ao } \\
\text { Capital Social } \\
\text { 5. Constituição de um fundo } \\
\text { para a educação dos } \\
\text { associados e do público em } \\
\text { geral } \\
\text { 6. Ativa cooperação entre as } \\
\text { cooperativas em âmbito } \\
\text { local, nacional e } \\
\text { internacional }\end{array}$ & $\begin{array}{l}\text { 1. Adesão Voluntária e } \\
\text { Livre } \\
\text { 2. Gestão Democrática } \\
\text { 3.Participação } \\
\text { Econômica dos Sócios } \\
\text { 4. Autonomia e } \\
\text { Independência } \\
\text { 5. Educação, Formação e } \\
\text { Informação } \\
\text { 6. Intercooperação } \\
\text { 7. Preocupação com a } \\
\text { Comunidade }\end{array}$ \\
\hline
\end{tabular}

Fonte: Schneider (1999), Crúzio (2005), Pereira et al. (2002).

Observando o Quadro 1, perceber-se que a Adesão Livre, a Gestão Democrática e a Educação, desde a atuação da ACI, estes princípios permanecem em todas as versões apresentadas; a Participação econômica dos sócios passa a englobar dois princípios, o Retorno pro rata das operações e o juros limitado ao capital investido; a Intercooperação só passou a ser considerada como princípio pela ACI em 1966, no Congresso de Viena; e a Autonomia e Independência e a Preocupação com a comunidade foram incluídos como princípios em 1995, em Manchester já na versão atual.

Assim, em vez de se constatar uma mudança na ideologia cooperativista, percebe-se que ao longo deste período, que inicia com o Estatuto de Rochdale e chega até a formulação dos princípios definidos em 1995, em Manchester, que as mudanças só reforçam as matrizes do movimento cooperativista (CANÇADO; GONTIJO, 2005).

A Adesão Voluntária e Livre, é o princípio que "trata de estabelecer os critérios básicos das relações do associado com a cooperativa e da cooperativa com o associado e de harmonizar essas relações" (SCHNEIDER, 2012, p. 259). Por se tratar do princípio foco desse estudo, o mesmo será explorado com maiores detalhes no próximo tópico. 
A Gestão Democrática é fundamental às cooperativas por demonstrar a importância dos sócios que, através da plena igualdade de votos, são os que ativamente tomam decisões, podem ser eleitos como representantes e podem fiscalizar todo o processo dentro das cooperativas (SCHNEIDER, 2012). Bertuol, Cançado e Souza (2012) afirmam que por meio da gestão democrática, nas assembleias, indivíduos que sejam de diferentes classes socioeconômicas se igualem dentro da cooperativa em termos de direitos, na qual podem expressar suas opiniões e defender seus direitos com os demais associados.

A Participação Econômica dos Sócios, funde dois princípios, a Distribuição das Sobras e a Taxa Limitada de Juros ao Capital Social respectivamente, pois ambos se referem a destinação das sobras que possivelmente venham ser geradas (SCHNEIDER, 2012). As cooperativas possuem duas vertentes, a econômica e a social, sendo que a essência deste princípio está em priorizar a pessoa e não o capital; também se destaca a destinação das sobras, quando as receitas são superiores as despesas, em que o cooperado pode ser remunerado proporcionalmente a sua participação, ou com juros limitado ao capital investido, se assim for decido em assembleia (BERTUOL; CANÇADO; SOUZA, 2012).

Autonomia e Independência, para Schneider (2012), essencialmente se refere a autogestão, ao controle que os sócios detêm, sendo que sua autonomia deve ser sempre preservada por mais que tenham ajudas externas. Apesar de só aparecer explicito no Congresso em Manchester em 1995, este princípio, segundo Cançado e Gotijo (2005), está diretamente relacionado com a da Gestão Democrática, pois possibilita que a participação do cooperado nas decisões não seja direcionada por entidades externas à cooperativa.

A Educação, Formação e Informação, visa que haja uma exata compreensão e ampla informação da "cultura cooperativa" a todos os envolvidos, sócios, representantes eleitos, administradores e funcionários (SCHNEIDER, 2012). Paredes e Loveridge (2018) e Maričić, Škorić, e Radenković (2018) entendem que este princípio funciona como motor para o atendimento aos demais princípios. Assim, o princípio da Educação, Formação e Informação torna-se de suma importância principalmente aos novos cooperados e funcionários, sendo recomendável que passem por uma formação educacional e sejam acompanhados neste processo afim de que os mesmos se identifiquem com o movimento e com a cooperativa, e de forma consciente exerçam funções que não os desviem da doutrina cooperativista (BERTUOL; CANÇADO; SOUZA, 2012).

A Intercooperação, inclui tanto as relações entre cooperativas da mesma classe ou do mesmo segmento, como as que existem entre as de segmentos diferentes e desta forma permite um fortalecimento e ampliação do movimento cooperativo viabilizando melhorias para reduzir riscos e ameaças e aproveitar as oportunidades (SCHNEIDER, 2012). A importância do princípio é constatada pela criação de federações e confederações, inclusive da própria Aliança Cooperativa Internacional, pois elas se ajudam mutualmente proporcionando uma maior possibilidade de crescimento e fortalecendo o movimento cooperativista (BERTUOL; CANÇADO; SOUZA, 2012).

A Preocupação com a comunidade, em consequência deste princípio, criado recentemente, o cooperativismo passa a ser uma das mais efetivas instâncias de desenvolvimento local e sustentável (Schneider, 2012). Apesar de apenas em 1995 ser considerado um princípio, já era dada importância a comunidade e ao seu desenvolvimento, uma vez que os associados são valorizados quando se defende a democracia e se incentiva a educação dos mesmos, pois tendem a estar vinculados à comunidade (CANÇADO; GOTIJO, 2005).

\section{A Adesão Voluntária e Livre}

A Adesão Voluntária e Livre na visão de Bertuol; Cançado e Souza (2012) está ligada à liberdade do indivíduo, sendo que suas necessidades e interesses influenciam na decisão de como elas serão atendidas, se escolhem ou não fazer parte de uma cooperativa. Cançado e Gontijo (2005) corroboram que as cooperativas não podem condicionar a utilização dos seus serviços com discriminação de sexo, classes sociais, raciais, políticas e religiosas. 
Para Schneider (2012) este princípio busca instituir os critérios considerados básicos que intermediam os vínculos entre os associados e a cooperativas e vice versa, subdividindo em três pontos para um melhor entendimento: adesão voluntária, significando a não obrigatoriedade em fazer ou não parte da cooperativa; adesão consciente, o indivíduo ao querer fazer parte da cooperativa deve saber, de forma prévia e clara todas as características, entendendo os seus direitos e deveres tanto os individuais como os coletivos; e adesão livre, sendo a cooperativa livre para admitir associados, na qual todos podem ser associados, contanto que reúnam condições que venham a somar aos objetivos defendidos pela cooperativa, complementando o sentido do princípio.

Observa-se que esta adesão "livre" fica limitada a certos fatores como Bertuol; Cançado e Souza (2012) esclarecem que um desses fatores refere-se aos objetivos e interesses que precisam ser comuns à cooperativa e o futuro associado; outro fator ou restrição pode ser quando o indivíduo que pretende tornar-se um associado já faça parte de uma empresa que seja concorrente da cooperativa; comentam também sobre o fator geográfico, visto que as cooperativas têm um âmbito de atuação delimitado, sendo necessário que o pretendente a cooperado resida dentro desta área de atuação da cooperativa.

Para que essas "limitações" sejam entendidas não como contraditórias ao princípio e sim como uma forma de proteção à cooperativa, que não incorpore pessoas que tenham os interesses individuais acima dos coletivos conforme Schneider (2012) explica, que não seja alguém que quer apenas usufruir de vantagens às custas do esforço dos outros, sem dar nada de pessoal em contrapartida aos benefícios recebidos graças ao empreendimento coletivo.

Höffling (2013) cita outra restrição, conhecida como "segmentação", que limitam a admissão de associados a indivíduos que exerçam uma determinada profissão ou atividade, ou que estejam vinculados a alguma entidade públicas e privadas, etc., pois as limitações de associados refletem no crescimento das cooperativas, visto que menos associados, são menos pessoas aptas a contribuir dentro da cooperativa. Höffling (2013) também esclarece que quem detém esse poder de incutir essa restrição é o órgão normativo de uma determinada atividade, que no caso das cooperativas de crédito que exercem atividade financeira é o Banco Central do Brasil.

A partir desse contexto, criou-se a hipótese de que quando mais restrições à adesão de novos associados, a cooperativa tende a ter menos sócios cooperados em seu quadro social.

\section{Procedimentos Metodológicos}

A necessidade de investigação dos possíveis impactos financeiros e educacionais da adoção do princípio da adesão voluntária e livre pelas cooperativas de crédito de Belém faz com que esta pesquisa se caracterize como aplicada, pois espera-se que seus resultados sejam utilizados pelas gestões das cooperativas de forma a corrigir possíveis problemas quanto à educação cooperativa e que sejam prudentes no sentido de resguardarem os princípios e valores cooperativistas aos novos sócios cooperados. E, o fato de não identificarmos estudos similares que se preocuparam com esse fenômeno, caracteriza a presente pesquisa como exploratória com abordagem qualitativa (CARMO E FERREIRA, 2008; GIL, 2008).

Por uma questão de representatividade em número de cooperados e crescimento econômico financeiro apresentado no relatório de gestão de OCB em 2018, esta pesquisa se concentrou no ramo de crédito. Por questão de disponibilidade dos dados em tempo hábil para a realização da pesquisa, foram escolhidas as cooperativas de crédito que estão localizadas na cidade de Belém, que estão dispostas no Quadro 2: 


\section{Quadro 2 - Relação das Cooperativas}

\begin{tabular}{|l|c|}
\hline \multicolumn{1}{|c|}{ Cooperativas } & \multicolumn{1}{|c|}{ Sigla } \\
\hline Cooperativa de Crédito de Livre Admissão do Estado do Pará. & SICOOB COOESA \\
\hline $\begin{array}{l}\text { Cooperativa de Crédito dos Integrantes do Ministério Público e do } \\
\text { Poder Judiciário nos Estados do Amapá e Ceará e Livre Admissão no } \\
\text { Estado do Pará. }\end{array}$ & SICOOB COIMPPA \\
\hline Cooperativa de Crédito. & SICREDI BELÉM \\
\hline $\begin{array}{l}\text { Cooperativa de Economia e Crédito Mútuo dos Servidores do Ministério } \\
\text { da Educação no Estado do Pará. }\end{array}$ & COOPERUFPA-CrediSIS \\
\hline $\begin{array}{l}\text { Cooperativa de Economia e Crédito Mútuo dos Servidores Públicos } \\
\text { Municipais da Região Metropolitana de Belém Ltda. }\end{array}$ & CREDBEM CREDISIS \\
\hline $\begin{array}{l}\text { Cooperativa de Crédito dos Servidores do Ministério da Agricultura, } \\
\text { Pecuária e Abastecimento na Região Metropolitana de Belém. }\end{array}$ & CREDISIS BELÉM \\
\hline $\begin{array}{l}\text { Cooperativa de Economia e Crédito Mútuo dos Empregados da } \\
\text { Eletronorte Ltda. }\end{array}$ & SICOOB UNIDAS \\
\hline $\begin{array}{l}\text { Cooperativa de Economia e Crédito Mútuo dos Servidores do Poder } \\
\text { Judiciário e Ministério Público Federal no Estado do Pará Ltda. }\end{array}$ & COOPERJUS \\
\hline
\end{tabular}

Fonte: Elaborado pelos autores (2019).

Ressalta-se que a última cooperativa (COOPERJUS), por se encontrar em processo de descontinuidade, não foi possível realizar a coleta de dados. Assim, de um universo de oito (8) cooperativas de crédito localizadas em Belém, a amostra final ficou composta por sete (7) cooperativas, caracterizando este estudo como um estudo de caso múltiplo com objetivo de explorar fenômenos atuais relacionados aos impactos financeiros e educacionais da adoção do princípio da adesão voluntária e livre pelas cooperativas da amostra (GIL, 2008).

A coleta dos dados foi realizada no período de junho a setembro de 2018. A primeira parte da coleta, de forma primária, se deu por meio de entrevistas semiestruturadas com os gestores das cooperativas de crédito em questão (tais entrevistas foram gravadas com autorização dos entrevistados). A segunda parte da coleta, de forma secundária, se deu na consulta aos Balanços Patrimoniais e Relatório de número de cooperados (coletados in loco), Estatutos Sociais (disponibilizados nos sites) das cooperativas nos períodos de 2015 a 2017; e por fim, ainda de forma secundária, foram acessados artigos, livros e outros trabalhos acadêmicos para o embasamento teórico da pesquisa.

A estratégia da entrevista semiestruturada se deu em função de deixar os entrevistados, nesse caso os representantes das cooperativas, com liberdade para responder as perguntas que foram previamente definidas, mas sem perder o foco do objetivo principal da pesquisa (GIL, 2008; BONI E QUARESMA, 2005).

Com o objetivo de propor uma discussão referente a adoção do princípio da adesão voluntária e livre com os possíveis impactos financeiros e educacionais nas cooperativas de crédito de Belém, na percepção dos seus gestores, buscando conhecer os objetivos dessa estratégia de capitação de novos sócios e se esses foram alcançados, adotou-se a técnica de pesquisa análise de conteúdo (BARDIN, 2011; MORAES, 1999).

De início, em planilhas eletrônicas, foi realizada a organização das informações coletadas. Então, tais informações foram individualizadas em: 1) Nome da Cooperativa e Sistema a qual pertence; 2) Identificação do Entrevistado; 3) Quem eram os cooperados na constituição e quem são agora? 4) A 
importância de aderir ao princípio da adesão voluntária e livre; 5) Dificuldades de ampliação da cooperativa; 6) Pontos negativos da adesão livre e voluntária; 7) Requisitos para ser um novo cooperado e; 8) Evolução do número de cooperados.

O próximo passo da análise de conteúdo consistiu em agrupar essas informações individualizadas em categorias de análise, então foram criadas duas categorias: 1 a Categoria de Análise - Quem são nossos cooperados? E, a 2 ${ }^{\underline{a}}$ Categoria de Análise - "Vantagens e Desvantagens da Livre Adesão". A partir dessas duas categorias foram realizadas a descrição e interpretação dos dados analisados (BARDIN, 2011; MORAES, 1999).

\section{Análises dos Resultados}

Para alcançar os objetivos propostos, buscou-se captar as informações relatadas por meio de entrevistas com os dirigentes das cooperativas as quais foram interpretadas e analisadas pela técnica de pesquisa análise de conteúdo (BARDIN, 2011), tendo como base as entrevistas realizadas com os gestores, os balanços patrimoniais e os estatutos sociais das cooperativas.

De acordo com a análise da primeira categoria "quem são nossos cooperados", três cooperativas da amostra (COOPERUFPA, CREDISIS e CREDBEM) acusaram ter seu quadro social composto somente de pessoas físicas (servidores públicos de vários órgãos), e até o momento das entrevistas, não tinham adotado a adesão voluntária e livre, no entanto, já diminuíram as restrições para novos sócios. As demais cooperativas investigadas (COIMPPA, COOESA, SICREDI e UNIDAS) sinalizaram que seu quadro social é composto tanto por pessoas físicas quanto por pessoas jurídicas (conforme o quadro 3). Ressalta-se que na análise dos estatutos sociais, todas as sete cooperativas permitem a admissão de pessoas físicas e jurídicas, porém como já comentado, nem todas possuem pessoas jurídicas em seu quadro social.

Quadro 3: Requisitos para ser um Cooperado

\begin{tabular}{|l|l|l|}
\hline Cooperativas & Na constituição & Atualmente \\
\hline COIMPPA & $\begin{array}{l}\text { Servidores do Ministério Público do Estado do } \\
\text { Pará }\end{array}$ & Pessoas Físicas e Pessoas Jurídicas \\
\hline COOESA & $\begin{array}{l}\text { Servidores da Assembleia Legislativa do } \\
\text { Estado do Pará }\end{array}$ & Pessoas Físicas e Pessoas Jurídicas \\
\hline COOPERUFPA & Servidores da UFPA & $\begin{array}{l}\text { Servidores públicos e profissionais da iniciativa } \\
\text { privada da área de educação }\end{array}$ \\
\hline CREDBEM & Funcionários da Câmara Municipal de Belém & $\begin{array}{l}\text { Servidores públicos da esfera municipal, } \\
\text { estadual e federal }\end{array}$ \\
\hline CREDISIS BELÉM & Funcionários da Embrapa & $\begin{array}{l}\text { Servidores dos órgãos do Ministério da } \\
\text { Agricultura, Pecuária e Abastecimento }\end{array}$ \\
\hline UICREDI & Profissionais da Saúde & Pessoas Físicas e Pessoas Jurídicas \\
\hline UNIDAS & $\begin{array}{l}\text { Sicoob Eletrocred que incorporou a Sicoob } \\
\text { Coopermater, Sicoob Fenão, Cooperdados, Coecelpa, } \\
\text { CooCPRM e Credieduc }\end{array}$ & Pessoas Físicas e Pessoas Jurídicas \\
\hline
\end{tabular}

Fonte: Elaborado pelos autores (2019).

Quanto à admissão das pessoas jurídicas, foi questionado aos gestores das sociedades cooperativas como fica a educação cooperativista? As quatro cooperativas que possuem em seu quadro social pessoas jurídicas, relataram que por tratar diretamente com os diretores das organizações que possuem "certo" grau de instrução, fica mais fácil o diálogo e a compreensão dos valores e princípios cooperativistas facilitando assim o atendimento do princípio da educação, 
formação e informação (SCHNEIDER, 2012). No entanto, não foram identificadas nas entrevistas ações de acompanhamento da efetividade da educação cooperativa trabalhada com esses diretores que representam as pessoas jurídicas na condição de associada às cooperativas.

Outro ponto a se destacar, segundo os gestores das cooperativas, refere-se ao fato das pessoas jurídicas apresentarem uma maior movimentação financeira nas cooperativas se comparado com as pessoas físicas, ou seja, utilização dos produtos e serviços, em maior volume o que é fator positivo para a entidade, uma vez que o consumo dos produtos e serviços oferecidos pela cooperativa é a principal operação de uma cooperativa de crédito o chamado ato cooperativo. Assim, observa-se que a captação de novos sócios cooperados na qualidade de pessoas jurídicas tem contribuído com a movimentação financeira das cooperativas o que caracteriza um fator de impacto positivo.

As quatro cooperativas que adotaram a livre adesão (COIMPPA, COOESA, SICREDI e UNIDAS) apresentam como única restrição, a atenção a alguns requisitos de proteção ao crédito que geralmente estão vinculados a uma norma. Mas que no geral, qualquer pessoa física ou jurídica podem ser um associado corroborando com Cançado e Gontijo (2005) ao defender a não discriminação do tipo de associado. Já as cooperativas COOPERUFPA, CREDBEM e CREDISIS ainda vinculam seus associados, respectivamente, ao funcionalismo público e à área de educação, aos servidores públicos da esfera municipal, estadual e federal e aos servidores dos órgãos do Ministério da Agricultura, Pecuária e Abastecimento. Observa-se que apesar de já terem diminuído suas restrições elas ainda seguem os dizeres de Machado (1975) ao restringir seus cooperados a um mesmo seguimento ou uma mesma classe profissional.

A partir da percepção dos gestores das cooperativas objeto dessa amostra, pode-se inferir que a livre adesão tem contribuído de forma positiva para a alavancagem financeira das cooperativas. Porém, não se pode fixar as metas apenas no fator financeiro sem a manutenção da essência do cooperativismo que se encontra fundamentada nos valores e princípios cooperativistas (SCHNEIDER, 2012). Nesse sentido, Dewangan e Dixit (2018) argumentam que o alicerce para a operacionalização adequada de uma sociedade cooperativa está baseado nos princípios e valores do cooperativismo, relatam ainda que dificilmente, uma cooperativa consegue ser sustentável e contínua, sem a observação aos princípios fundamentais do cooperativismo.

Assim, chama-se atenção aos cuidados referentes a percepção desse novo cooperado quanto ao entendimento de que ele é dono e ao mesmo tempo cliente da cooperativa, assim como, a percepção dos gestores quanto à compreensão de que estão admitindo não apenas novos correntistas, mas também novos sócios-cooperados.

$\mathrm{Na}$ fala da diretora administrativa e financeira da COIMPPA, é possível observar essa preocupação "a mentalidade limitada de entender que é seu o negócio, há uma dificuldade em interiorizar essa cultura cooperativa"... "no banco você abre uma conta e paga a tarifa como um simples cliente e na cooperativa você faz parte do negócio com a sua cota"... "o dinheiro que gira dentro da cooperativa é do cooperado e toda sobra volta para ele proporcionalmente à sua participação na movimentação dos serviços disponibilizados".

A gerente da CREDISIS BELÉM, em relação a essa percepção dos que procuram a cooperativa para admissão, comenta que "geralmente, eles não têm consciência do que são as cooperativas e que o retorno vai vir pra eles, se enrolam nos bancos, só procuram as cooperativas em último caso", observase nesse momento a importância de um programa de educação cooperativa para esses novos sócios. De forma contrária, na CREDBEM, o gerente geral evidencia que seus associados demonstram interiorizar o sentimento de que também são proprietários e clientes da cooperativa ao relatar que "são dois momentos que o cooperado participa, como dono e como cliente, então ele passa a ter zelo, pois aquilo é dele e se der errado ele vai pagar pelo erro".

A partir da análise da primeira categoria (quem são nossos cooperados?), foi possível observar que tanto pessoas jurídicas quanto pessoas físicas fazem parte do quadro social das cooperativas em análise e que apesar da importante contribuição financeira, em especial das pessoas jurídicas, os 
gestores das sociedades cooperativas demonstram preocupação quanto à educação cooperativa desses novos sócios, pois admitem que muitos só procuram a cooperativa quando já esgotaram seu crédito com os bancos e a maioria deles não entendem de fato o que significa ser um cooperado e como funciona a cooperativa de crédito. Apesar desse contexto, em nenhuma das sete cooperativas em análise foi identificado algum programa de educação cooperativa para novos sócios cooperados, inclusive sendo admitido pela maioria dos entrevistados como uma falha que precisa ser corrigida.

Na segunda categoria de análise "Vantagens e Desvantagens da Livre Adesão" observou-se que das sete cooperativas pesquisadas, apenas a CREDBEM sinalizou de forma negativa para a livre adesão. Os gestores das demais cooperativas (COIMPPA, COOESA, COOPERUFPA, CREDISIS, SICREDI E UNIDAS) sinalizaram concordar que a livre adesão é um fator positivo para as cooperativas de crédito (SCHNEIDER, 2012), pois possuem a possibilidade de não ficar num grupo restrito o que diminui a fluxo financeiro e, ainda entendem como uma das principais estratégias competitivas frente aos bancos.

O diretor geral da CREDBEM, mesmo admitindo que chegará um momento que não terá como não aderir a livre adesão, em sua fala ficou explicito a negativa "no momento não se cogita ser de livre admissão"..."há grande resistência do grupo", demonstrando a objeção dos associados com o seguinte exemplo "se entra um grupo de mil associados e eles botam uma chapa, concorrem, e ganham a administração"..."talvez eles não tenham a visão dos 25 anos de existência da cooperativa, de que sempre foi bem administrada com grande zelo". Nesse momento, observa-se que esse receio dos sócios (antigos) pode estar atrelada a uma falha da educação cooperativa, pois acredita-se que quando os sócios conhecem o histórico da cooperativa e entendem o funcionamento da mesma, dificilmente não conseguiriam geri-la, porém para isso, precisariam passar por um processo educacional voltado ao cooperativismo.

A diretora Administrativa da COIMPPA comenta que a livre adesão impacta diretamente outro princípio cooperativista, "preocupação com a comunidade" pois, relata que ao abrir para outras pessoas a possibilidade de serem cooperadas, está dando a oportunidade de melhorarem de vida, uma vez que poderão fazer uso dos serviços da cooperativa, o que pode ser interpretado como um impacto positivo.

O gerente de negócios da UNIDAS, ao comentar a relevância da livre adesão relata que "abriu um espaço muito maior para as cooperativas dentro do sistema financeiro e isso fez com que a comunidade como um todo tivesse uma outra opção de serviço bancário e de serviços financeiros", enfatizando que esse crescimento das cooperativas de crédito tem como diferencial "ofertar essa humanização de valores, de negócios, humanização do crédito e das relações financeiras".

De acordo com a presidente do conselho de administração da SICREDI, "buscar um novo mercado é muito bom, ampliar e poder atender a todos que nos procuram. Ainda estamos engatinhando no cooperativismo, mas na Espanha, por exemplo, quem regula o mercado são as cooperativas; no sul do Brasil também o cooperativismo já tem muita força".

O gerente da COOPERUFPA, argumenta que "o aumento do número de cooperados gera consequentemente o crescimento da cooperativa e do cooperativismo, quanto maior for a base, mais pessoas teremos para usar nossos produtos. 0 objetivo maior é poder oferecer produtos de qualidade com taxas e juros menores que a do mercado".

A partir do argumento anterior, novamente, cabe uma reflexão referente a qualidade desses novos cooperados. Até que ponto essas cooperativas estão se preocupando com a educação cooperativa desses novos sócios? Existe algum projeto ou política de educação cooperativa para esses associados? Como já comentado, estão admitindo novos sócios ou apenas correntistas em busca de serviços financeiros com juros mais baixos? Esses são alguns questionamentos que surgem nesse processo de análise.

A gerente da CREDISIS BELÉM explica que não há treinamento ou algum tipo de curso para o novo associado em relação a uma conscientização sobre os princípios e valores do cooperativismo, 
apenas há uma conversa em que se tenta aprofundar sobre o assunto e que o próprio associado não se dispõe em querer saber, e que "eles vêm geralmente aqui porque nós temos um plano de saúde muito atrativo", mas percebe que é uma falha da cooperativa e complementa dizendo "no momento não temos estrutura".

A diretora financeira da COOESA relata, por exemplo, que "qualquer pessoa pode ser um novo associado, inclusive pessoa jurídica; agora quando entra temos que saber se não estamos trazendo uma pessoa "problemática" que venha trazer problemas para a cooperativa. Antes, o novo cooperado passava por uma avaliação, uma análise que era feita por um técnico e em alguns casos também pela diretoria. Esse cooperado precisava passar por curso sobre cooperativismo, hoje não há a necessidade, o cooperado pode se informar quando quiser pela internet em uma plataforma que é disponibilizada a ele", fato este que consideramos preocupante, pois este procedimento é analisado como um ponto negativo.

No entanto, observa-se que existe a preocupação de alguns dirigentes quanto aos valores e princípios cooperativistas, a diretora financeira da COOESA, por exemplo, argumenta que "muita coisa precisa mudar para nos adequarmos à livre adesão e outras precisam ser preservadas pois não podemos deixar perder a essência do cooperativismo". Na COIMPPA, o presidente do conselho de administração diz que "o Sicoob buscando melhorar a visão cooperativista tanto dos cooperados quanto da comunidade criou o Instituto Sicoob, em que colaboradores e associados são treinados e trabalham voluntariamente como instrutores, para o fortalecimento da Educação Cooperativista e para a Educação Financeira".

Partindo do pressuposto de que para se associar a uma cooperativa considera-se apenas o interesse ou não do indivíduo, sem nenhum tipo de distinção (CANÇADO; GONTIJO, 2005), e que em tese, com a adoção da adesão livre e voluntária e respectiva diminuição ou exclusão das restrições, deveria ocorrer o aumento de cooperados (HÖFFLING, 2013) observam-se resultados que convergem com a teoria apresentada, pois a CREDSIS e a CREDBEM ainda apresentam restrições quanto a adesão de novos associados o que refletiu uma diminuição no seu quadro social no período analisado, confirmando assim a hipótese de que quando mais restrições à adesão de novos associados, a cooperativa tende a ter menos sócios cooperados em seu quadro social.

Por conseguinte, observa-se que na COIMPPA, COOESA, SICREDI e UNIDAS as quais já adotaram a livre adesão, o número de associados aumentou no período analisado, o que reforça a hipótese em questão. No entanto, o caso da COOPERUFPA, chama a atenção pelo fato de ainda não ter aderido à livre adesão, no entanto, apresentou um aumento em seu quadro social, como pode ser observado no Quadro 4. Acredita-se que este fato deve-se ao processo de transição pelo qual passa a COOPERUFPA, pois seu gerente relata que o processo da livre adesão está em pauta de discussão nas assembleias, e que, na verdade já iniciaram esse processo, porém ainda não o concluíram.

Quadro 4 - Evolução de cooperados

\begin{tabular}{|l|c|c|c|c|r|c|}
\hline \multirow{2}{*}{ Cooperativa } & \multicolumn{5}{|c|}{ Número de Cooperados } \\
\cline { 2 - 7 } & Na constituição & $\mathbf{2 0 1 5}$ & \multicolumn{2}{|c|}{$\mathbf{2 0 1 6}$} & \multicolumn{2}{c|}{$\mathbf{2 0 1 7}$} \\
\hline COIMPPA & 55 & 1799 & 1909 & $6,1 \%$ & 2018 & $12,2 \%$ \\
\hline COOESA & 42 & 1616 & 2113 & $30,8 \%$ & 2635 & $63,1 \%$ \\
\hline COOPERUFPA & 82 & 2704 & 2763 & $2,2 \%$ & 2867 & $6,0 \%$ \\
\hline SICREDI & 57 & 2172 & 2185 & $0,6 \%$ & 2378 & $9,5 \%$ \\
\hline UNIDAS & 4200 & 4114 & 5178 & $25,9 \%$ & 6069 & $47,5 \%$ \\
\hline CREDBEM & 35 & 273 & 244 & $-10,6 \%$ & 261 & $-4,4 \%$ \\
\hline CREDISIS BELÉM & 35 & 433 & 446 & $3 \%$ & 429 & $-0,9 \%$ \\
\hline
\end{tabular}

Fonte: Elaborado pelos autores, dados da pesquisa (2019). 
Outro ponto de destaque está na alteração do saldo da conta capital social e sua relação com o número de cooperados, pois se a cooperativa apresenta um aumento do número de cooperados em seu quadro social, em tese, deveria apresentar um aumento na conta capital social, o que pode ser evidenciado nas cooperativas COIMPPA, COOESA, COOPERUFPA (Quadro 5).

A SICREDI e UNIDAS mesmo com o aumento no número de cooperados, apresentou uma diminuição de capital social, o que pode ser evidenciado no quadro 5. Fato este que pode ser explicado pelo processo de fusão pela qual a mesma passou nos últimos anos, conforme informação de seus gestores.

No entanto a CREDBEM e a CREDISIS, foram as únicas que apresentaram uma redução no número de cooperados (Quadro 4) mas que não as impossibilitaram de aumentarem a conta de capital social (Quadro 5), que pode ser justificado pela retenção de saldos positivos nas contas de reservas e/ou fundos.

Quadro 5 - Capital Social das Cooperativas (em milhares de reais)

\begin{tabular}{|c|c|c|c|}
\hline Cooperativas & $\mathbf{2 0 1 5}$ & $\mathbf{2 0 1 6}$ & $\mathbf{2 0 1 7}$ \\
\hline COIMPPA & 39.494 & 45.107 & 49.292 \\
\hline COOESA & 8.892 & 9.673 & 10.295 \\
\hline COOPERUFPA & 14.133 & 15.442 & 16.200 \\
\hline SICREDI & 20.455 & 24.017 & 23.181 \\
\hline UNIDAS & 20.851 & 19.808 & 17.555 \\
\hline CREDBEM & 4.554 & 4.896 & 5.359 \\
\hline CREDISIS BELÉM & 1.153 & 1.320 & 1.423 \\
\hline
\end{tabular}

Fonte: Elaborado pelos autores, dados da pesquisa (2019).

Em síntese, os diretores das cooperativas da amostra não apontam pontos negativos e sim sinalizam desafios, ao processo de adoção da livre adesão, pois antes tinham o empréstimo consignado descontado em folha como uma das principais operações, sendo o risco de inadimplência praticamente zero. Agora as cooperativas aumentaram seu mix de produtos e serviços, passando a transacionar com um número maior de pessoas com um risco considerável, o que demanda uma qualificação mais acentuada dos colaboradores. Nesse sentido, a diretora financeira da COOESA argumenta: "não que seja ruim, mas temos que trabalhar para o mercado financeiro e isso exige uma maior qualificação, um maior investimento e paralelamente cresce as exigências, os controles internos e externos".

Assim, observa-se outro impacto positivo quanto a livre adesão, só que agora no campo educacional e social e a justificativa para essa qualificação soma-se ao fato da necessidade de maior rigor na análise de crédito aos cooperados.

\section{Conclusões}

A presente pesquisa propôs uma discussão referente a adoção do princípio da adesão voluntária e livre com os possíveis impactos financeiros e educacionais nas cooperativas de crédito de Belém, na percepção dos seus gestores, buscando conhecer os objetivos dessa estratégia de captação de novos sócios e se esses foram alcançados. 
A partir dos resultados analisados das cooperativas de crédito da amostra, foi possível identificar que a adoção do princípio da adesão voluntária e livre tem provocado impactos nas cooperativas, tanto sob o aspecto financeiro quanto educacional.

Quanto aos impactos financeiros, observa-se que a admissão de novos sócios cooperados provoca a entrada de capital nas cooperativas devido a integralização das cotas-partes, e, que pode ser interpretado como um impacto positivo. Esta análise foi possível a partir do quadro 4 que evidenciou a evolução do quadro social das cooperativas em análise. Ressalta-se que esta evolução foi refletida no patrimônio líquido, na conta capital social das cooperativas. Observa-se também que mesmo a COOPERUFPA ainda não tendo adotado totalmente ao princípio mas apenas pelo fato de ter diminuído as restrições para novos sócios, também provocou um aumento no seu quadro social e respectivamente no capital social da mesma.

Destaca-se que a CREDBEM e a CREDISIS mesmo não apresentando um aumento no número de sócios cooperados, apresentaram um aumento no capital social, que pode ser explicado pela retenção de saldo positivo de capital em seu patrimônio líquido.

Quanto aos impactos educacionais, foi observado que alguns dirigentes apresentam preocupação, pois sabem que existem muitos novos sócios cooperados que não possuem conhecimentos dos valores e princípios cooperativistas e que no caso das cooperativas de crédito, se candidatam a sócios por uma oportunidade de crédito financeiro. Por não conhecer o funcionamento das cooperativas, acabam ficando restrita apenas obtenção de empréstimos ou consignados ou mesmo de plano de saúde disponibilizados por convênios com as operadoras de planos, deixando de usufruir de outros benefícios proporcionados pela cooperativa.

Mesmo sendo consciente deste cenário, não foi identificado em nenhuma das cooperativas em análise, um programa efetivo de educação cooperativa para novos sócios cooperados, que tivesse o objetivo de trabalhar com esses novos sócios o funcionamento da cooperativa em questão demonstrando seus direitos e obrigações enquanto cooperados, assim como, os valores e princípios cooperativistas para que consigam preservar a essência do cooperativismo e que as cooperativas não se transformem apenas em um banco comercial, pois existe uma grande diferença entre ser uma cooperativa de crédito e um banco comercial e essa diferença está baseada nos valores e princípios cooperativistas.

Em relação a identificar se as cooperativas atingiram seus objetivos com as políticas de admissão de novos sócios, observa-se que se o objetivo era adquirir novos sócios para a promover a capitalização da cooperativa, esse objetivo foi atingido, no entanto, com ele surgiu um problema que está relacionado a educação desses novos sócios que pode, num futuro próximo colocar em risco a continuidade das mesmas por falta de coesão e surgimento de conflitos de interesses.

A partir da identificação desses impactos sob o aspecto financeiro e educacional, a presente pesquisa atinge seu objetivo principal e ao mesmo tempo responde sua questão de pesquisa. Ressaltase também que com os resultados da pesquisa, foi possível confirmar a hipótese de que quando mais restrições à adesão de novos associados, a cooperativa tende a ter menos sócios cooperados em seu quadro social. Pois, as cooperativas que aderiram totalmente à livre adesão, apresentaram um aumento considerável no seu quadro social e respectivamente no seu capital social com a subscrição e integralização de novas cotas.

A dificuldade de conseguir os dados completos para análise de um número maior de cooperativas configura-se como a principal dificuldade encontrada pois o planejamento inicial era trabalhar com todas as cooperativas de Belém que tinham adotado ou iniciado a adoção ao princípio da adesão voluntária e livre.

Assim, como sugestão para pesquisas futuras recomenda-se num maior prazo envolver todas as cooperativas do estado do Pará que aderiram ao princípio da adesão livre e voluntária para tentar confirmar esses resultados encontrados nas cooperativas de Belém e identificar outras possíveis 
preocupações além da questão educacional dos novos cooperados e quais estratégias as cooperativas estão adotando para desenvolver essa educação.

\section{REFERÊNCIAS}

ALIANÇA COOPERATIVA INTERNACIONAL (Bélgica). Co-operative identity, values \& principles. Disponível em: https://www.ica.coop/en/cooperatives/cooperative-identity. Acesso em: 06 abr. 2019.

BANCO CENTRAL DO BRASIL (BACEN). Panorama do Sistema Nacional de Crédito Cooperativo 2016. Disponível em: https://www.bcb.gov.br/pre/microFinancas/coopcar/pdf/panorama_de_cooperativas.pdf. Acesso em: 10 mar. 2019.

BANCO CENTRAL DO BRASIL (BACEN). O que é cooperativa de crédito? Disponível em: https://www.bcb.gov.br/estabilidadefinanceira/cooperativacredito. Acesso em: 11 mar.2019.

BARDIN, L. Análise de conteúdo. Edições 70. Lisboa. Portugal, 2011.

BERTUOL, R.; CANÇADO, A. C.; SOUZA, M. F. A. A prática dos princípios cooperativistas: um estudo de caso no Tocantins. Amazônia, Organizações e Sustentabilidade, Belém, v. 2, n. 1, p.7-18, ago. 2012.

BONI, V.; QUARESMA, S. J. Aprendendo a entrevistar: como fazer entrevistas em Ciências Sociais. Em Tese, v. 2, n. 1, p. 68-80, 2005.

BRASIL. Lei no 5.764, de 16 de dez. de 1971.Diário Oficial (da República Federativa doBrasil), Brasília, DF, 16 de dez. 1971.

BRASIL. Resolução № 3.106 (2003). Funcionamento de cooperativas de crédito. Disponível em: https://www.bcb.gov.br/pre/normativos/busca/downloadNormativo.asp?arquivo=/Lists/Normativo s/Attachments/46578/Res_3106_v5_P.pdf. Acesso em: 06 jun. 2019.

BRASIL. Resolução № 4.434 (2015). Funcionamento de cooperativas de crédito. Disponível em: https://www.bcb.gov.br/pre/normativos/busca/downloadNormativo.asp?arquivo=/Lists/Normativo s/Attachments/48507/Res_4434_v3_P.pdf. Acesso em: 06 jun. 2019.

CANÇADO, A. C.; SOUZA, M. F. A.; PEREIRA, J. R. Os princípios cooperativistas e a identidade do movimento cooperativista em xeque. Revista de Gestão e Organizações Cooperativas, v. 1, n. 2, p. 51$62,2014$.

CANÇADO, A. C.; GONTIJO, M. C. H. Princípios cooperativistas: origem, evolução e influência na legislação brasileira. Encontro de Investigadores Latino-Americanos de Cooperativismo, v. 3, 2005.

CARMO, H.; FERREIRA, M. Metodologia da Investigação-Guia para Auto-aprendizagem (2 $2^{\mathrm{a}}$ edição). Lisboa: Universidade Aberta, p. 001-89, 2008.

CHARTERINA, A. M. Los valores y los principios cooperativos. REVESCO: revista de estudios cooperativos, n. 61, p. 35-46, 1995.

CRÚZIO, H. O. Como organizar e administrar uma cooperativa. Rio de Janeiro: Editora FGV, 2005.

DEWANGAN, A.; DIXIT, A. A Review of Problems and Challenges of Cooperative Societies. Clear International Journal of Research in Commerce \& Management, 2018, 9.8.

GERIZ, S. D. As cooperativas de crédito no arcabouço institucional do sistema financeiro nacional. Prim@ Facie-Direito, História e Política, v. 3, n. 4, p. 82-110, 2004. 
GIL, A. C. Métodos e técnicas de pesquisa social. 6. ed. Ediitora Atlas SA, 2008.

HÖFFLING, A. R. O impacto da livre admissão de associados sobre o desenvolvimento das cooperativas de crédito. 2013. Dissertação (Mestrado em Direito) - Universidade Católica de Brasília, Brasília, Brasil. 2013.

MACEDO, V. S.; FREIRE, D. C. Desenvolvimento do cooperativismo de crédito, com ênfase na cooperativa Credisis RolimCredi. Revista FAROL, v. 5, n. 5, p. 208-235, 2017.

MACHADO, P. A. Comentários à lei do cooperativismo. Editoras unidas, 1975.

MARIČIĆ, G.; ŠKORIĆ, S.; RADENKOVIĆ, D. Application of the principles of corporate governance in agriculture cooperatives. Economics of Agriculture, 2018, 65.2: 827-841.

MEINEN, E.; PORT, M. O cooperativismo de crédito ontem, hoje e amanhã. Brasília: Confebras, 2012.

MORAES, Roque. Análise de conteúdo. Revista Educação, Porto Alegre, v. 22, n. 37, p. 7-32, 1999.

ORGANIZAÇÃO DAS COOPERATIVAS BRASILEIRAS- PARÁ. Ramo Crédito. Disponível em: http://paracooperativo.coop.br/cooperativismo/ramos-do-cooperativismo/8-credito. Acesso em: 10 dez. 2018.

ORGANIZAÇÃO DAS COOPERATIVAS BRASILEIRAS. A força do cooperativismo de crédito. Disponível em: https:// www.ocb.org.br/noticia/21255/a-forca-do-cooperativismo-de-credito. Acesso em: 15 dez. 2018.

ORGANIZAÇÃO DAS COOPERATIVAS BRASILEIRAS. O que é Cooperativismo. Disponível em: https://www.ocb.org.br/o-que-e-cooperativismo. Acesso em: 15 dez. 2018.

PAREDES, D.; LOVERIDGE, S. Rural electric cooperatives and economic development. Energy policy, 2018, 117: 49-57.

PEREIRA, J. R. et al. As Organização da sociedade através das cooperativas de trabalho: abordagem dos problemas e perspectivas. Viçosa, UFV, 2002.

PINHO, D. B. 0 cooperativismo no Brasil: da vertente pioneira à vertente solidária. Saraiva, 2004.

PORTAL DO COOPERATIVISMO FINANCEIRO. Cooperativas de Livre Admissão: 15 anos. Disponível em: https://cooperativismodecredito.coop.br/2019/01/cooperativas-de-livre-admissao-15- anos/. Acesso em: 06 jan. 2019.

PORTAL DO COOPERATIVISMO FINANCEIRO. Os 7 princípios do cooperativismo. Disponível em: https://cooperativismodecredito.coop.br/cooperativismo/historia-do-cooperativismo/os-7principios-do-cooperativismo/. Acesso em: 06 jun. 2019.

SCHNEIDER, J. O. Democracia, participação e autonomia cooperativa. Editora Unisinos, 1999.

SCHNEIDER, J. O. A doutrina do cooperativismo: análise do alcance, do sentido e da atualidade dos seus valores, princípios e normas nos tempos atuais. Cadernos Gestão Social, v. 3, n. 2, p. 251-273, 2012.

SILVA, P.; SANTOS, R. A.; OLIVEIRA, A. C.; Doutrina e Princípios Cooperativista: Um Estudo de Caso na Cooperativa Maxi Mundi. Revista Científica do ITPAC. Araguaína, Tocantins, 2012.

SINGER, P. Introdução à economia solidária. Fundação Perseu Abramo, 2002. 